\title{
Next Generation Rural Wireless Connectivity Model for Developing Countries
}

\author{
A.H.M. Razibul Islam ${ }^{1}$, Rishad Ahmed Shafik ${ }^{2}$, Md. Imrul Hassan ${ }^{1}$ and Ju Bin Song ${ }^{1}$ \\ 'Department of Radio Communication Engineering, Kyung Hee University, Suwon, 449-701, \\ South Korea, Telephone: +82-31-201-3277,E-mail: razib3002@gmail.com \\ ${ }^{2}$ Department of Electrical and Electronic Engineering, Islamic University of Technology, \\ Boardbazar, Gazipur-1704, Bangladesh,E-mail: rishad09@gmail.com
}

\begin{abstract}
Next generation wireless technology with converged voice and data applications can offer rural connectivity for proper boost in Information and Communication Technology (ICT). In this study, a cost-effective ICT based solution for economic development of rural community in developing countries using appropriate next generation wireless networking technology has been represented. In the target country, Bangladesh, several Wireless Rural Points (WRPs) in a village will be connected to the local server of the village called Wireless Access Point (WAP). Each of several WAPs will be connected to several Rural Resource Servers (RRSs) and thus will form a Rural Resource Network (RRN). Adopting the proposed model with the existing ICT infrastructure of the target country can provide significant economic development therefore for the rural community. A similar implementation in other developing countries can offer a massive success.
\end{abstract}

\section{Introduction}

$85 \%$ of the population of least developed countries (LDC) and $75 \%$ Asian people of developing countries are living in rural areas. The accessibility and availability of ICT is even lower in rural areas than the urban areas of the developing countries. An unprecedented positive impact on the economic and social development of the rural areas of developing regions can be observed by harnessing ICT through the wireless infrastructure. The scope of this paper therefore encompasses a proposed rural wireless connectivity model with next generation technologies and its socio-economic implications in developing countries.

Deployment strategy of next generation communication technology needs to be cost-effective as well-which has been taken into consideration in this paper. In this study, as a target country, Bangladeshlying in the north-eastern part of South-Asia is considered as a representation of the developing countries. $80 \%$ of the total population (138.23 million) of Bangladesh lives in rural areas and the landline telecommunication infrastructure is not at all in favour of them. The remote corners of the country cannot be reached by landline telephone network due to large number of rivers, canals or marshy islands. As a result, the socio-economic status is very poor as they cannot actively take part in business opportunities with their commodities and so on.

Hence, Bangladesh as a target country is a good representative of developing countries to incorporate a wireless connectivity model for the rural community development.

The paper starts with the existing ICT infrastructure of the target country, Bangladesh in section 2. Section 3 deals with the proposed connectivity model. Section 4 narrates the implications on the rural community of the proposed model in rural economic development and finally ends with a summarization and future directions in section 5 .

\section{ICT infrastructure of target country}

In the target country, Bangladesh, fixed line teledensity is 0.69 and mobile phone teledensity is about 2.0. Bangladesh Telephone and Telegraph Board (BTTB), a state enterprise, dominates the fixed 
line sector. There are four private operators licensed to provide wireline network services in rural areas: Bangladesh Rural Telecommunications Authority (BRTA), Sheba Telecom, Gulf Bangladesh and Bangladesh Telecom Limited (BTL). At least three out of about two dozen licensed private companies Bayphones and RanksTel - have rolled out networks in the south-eastern Chittagong and Sylhet divisions offering the first private fixed-line phones to residents, thus curbing the monopoly of BTTB. BTTB has 671 telephone exchanges, 950,000 fixed lines and 806,000 subscribers. Bangladesh now has five cell phone operators - CityCell, Grameen Phone (GP), AKTEL, Banglalink in the private sector and Teletalk in the public sector. Recently, Warid Telecom has launched to be the sixth mobile phone operator in Bangladesh. The number of mobile subscribers in Bangladesh, which is currently 9 million, is expected to reach around 21 million by December 2007 with a penetration rate of 14 per cent against 6 percent at present. $1800 \mathrm{~km}$ long fiber optic network under Bangladesh Railway is being utilized by GP $(67 \%$ market share) as an exclusive 100 year deal with the Railway Corporation. Fiber optic links are established in most cities of the country (50 out of 64 districts) by BTTB. GSM 900 and $1800 \mathrm{MHz}$ frequency bands are enjoyed by GP and others use GSM-900 MHz and only Citycell uses CDMA and AMPS $800 \mathrm{MHz}$ systems for their services.

In June 1996, upon VSAT (Very Small Aperture Terminal) satellite link commissioning, the first internet connection was established and email and web service were launched to the Bangladeshi public. Number of computers is about 0.5 million of about 0.1 million internet users. Number of ISPs has grown to 195 with individual bandwidth ranging from $64 \mathrm{Kbps}$ to $2 \mathrm{Mbps}$, offering broadband internet services through DSL/HDSL modems. All 64 districts and 35\% of sub-districts of Bangladesh have been brought under Internet coverage by BTTB through dial-up connections. But in reality, current VSAT (satellite link) data circuits are with low bandwidth (up to 128 kbps) and high latency (greater than 500ms one way).BTTB has recently completed a project to connect Bangladesh with the information superhighway through 800 miles long submarine fiber-optic cable project SEA-WE-MEA4 with a landing site at Cox's Bazar. Also, Bangladesh PDB (Power Development Board) has ready-made power network all over the country that could be used costeffectively to hang/overlay fiber optic cables for building up the missing links of countrywide ICT infrastructure along with fiber optic backbones possessed by BTTB and Bangladesh Railway.
But in a riverine country like Bangladesh, specially in the rural areas, it will be very expensive to implement fiber optic connections at the remote locations. So, broadband wireless Internet access in the rural areas can be a very good solution in a country like Bangladesh which has small area, is densely populated and has low teledensity. At the same time, existing fiber optic backbone can also be integrated to the rural wireless networks to offer a cost-effective solution as because the fiber optic backbone should not be left unused.

\section{Proposed model}

\subsection{Brief description of the model}

In our proposed model, in the target countryBangladesh, a cost-effective rural connectivity approach is implemented by wirelessly stationary end point method which can be termed as Wireless Rural Point (WRP).In order to minimize the costs, unnecessary large coverage area will not be required initially to provide mobility elsewhere in a village. So, WRPs will be located in important locations of a village like markets, schools, offices etc. using lower transmission frequencies (LTF) with multihop or mesh network strategy. Bi-directional antennas can be costeffective for targeted end point coverage. A typical "24 dBi" antenna, which costs about US \$ 80 in India, enables hot spot coverage with megabits of coverage that are more than $30 \mathrm{~km}$ from the tower. These kinds of antennas are being used in Bangladesh for nonmobile village phones of GP. For the stationary endpoint method, a lower transmission frequency (LTF), such as $450 \mathrm{MHz}$ for CDMA450 or $700 \mathrm{MHz}$ has been proposed in India. In low density rural areas, these frequencies are proved to be cheaper as for a given distance the number of cells will be few or bandwidth will be high. Several WRPs will be connected by a central Wireless Access Point (WAP). WAP will be the local server for a village and it will be connected to the IP backbone environment provided by BTTB. Several WAPs will form a Rural Resource Network (RRN). A Rural Resource Server (RRS) will be connected to a WAP and RRSs will be connected with the central server to form the RRN. Fig.1 shows the diagram of the proposed model.

\subsection{Rural resource network (RRN) concept}

RRN will be responsible to integrate the requests made by each WAP and find solution for any queries made by the local telecenters of WAPs. The RRN will 


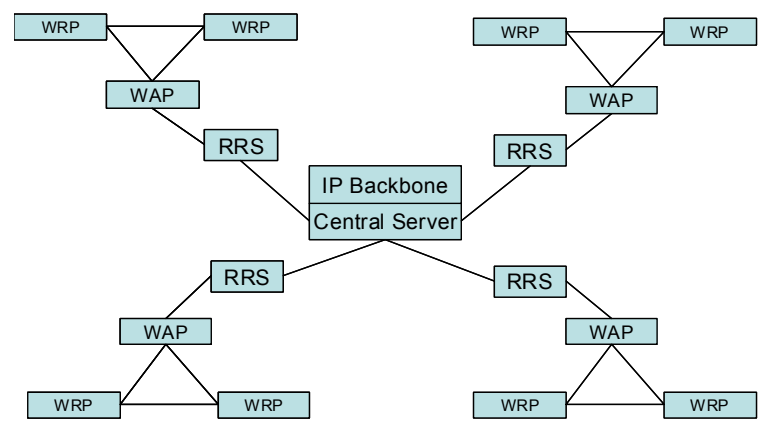

Figure 1. Proposed model of the infrastructure

connect the telecenters of different villages and thus the telecenters will have the Internet connectivity as well as WRP access. Computer literate telecenter staffs will act as intermediaries between community members who may require information though they are not familiar with ICT. The updated information about agriculture, market commodities price lists, job information, disaster information, weather forecasts will be sent from the RRS to each WAP and Multimedia Messaging Service (MMS) or Short Messaging Service (SMS) can be used to deliver the updated information on request by each WRP via WAP.

Traffic management of different applications such as e-transaction, web browsing, mobile transaction etc. will be managed in the RRSs by traffic monitor software by the priority of the service keeping into consideration the transmission delay, bandwidth requirement etc. RRN will be divided into two levels where the administrative people will take care of the decision making aspects and management of central server and RRS, security issues related with mobiletransactions or e-commerce. The user level will enrich the contents of the central server of RRN with the updated information and co-ordinate with the WAPs for information delivery. They will work under the guidance of administrative level.

\subsection{Cost-effectiveness of the system}

Rural service demands are best met gradually, beginning with low bandwidth sufficient to provide basic communications services that people demand the most-e.g. voice, while simultaneously laying the groundwork to expand as incomes and demand grow[4]. Acknowledging this idea, the throughput requirement specified by most of the auctions in South America is in the range of $128 \mathrm{kbps}$ to $256 \mathrm{kbps}$ per access point.

For fixed wireless connectivity in rural areas like Wireless Local Loop (WLL), CDMA 2000 mobile standard can also offer $153 \mathrm{kbps}$ throughput for the last mile approach other than CDMA450 and CDMA700. Zapp networks in Romania were able to establish connectivity by CDMA450 standard for non-mobile endpoints at a distance of $50 \mathrm{~km}$ with data connectivity of $1.3 \mathrm{Mb} / \mathrm{s}$ (uplink was $110 \mathrm{kbps}$ ).

IEEE $802.11 \mathrm{~b} \& \mathrm{~g}$ operate at $2.4 \mathrm{GHz}$; have 3 channels each and cover about 100 feet; 802.11a operates at $5 \mathrm{GHz}$ band, has 24 channels and covers 75 feet which requires more antennas. So maintaining large WiFi (IEEE 802.11a, b \& g) networks with many

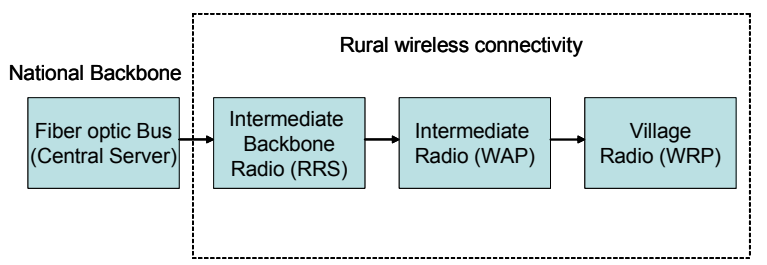

Figure 2. Adaptive framework for radio connectivity with the existing fiber optic backbone

antennas will not be a good choice initially as it will augment complexity. But, using multihop mesh networking solutions with WiFi networks [5] for hilly areas for longer range connectivity can offer a minimized cost for towers.

Non-line of sight (NLOS) wireless mechanisms are emerging with cost effective options for deploying multi megabit Internet service with ranges of 20 to 50 miles. NLOS wireless mechanisms use smart antennas, advanced modulation techniques and mesh architecture to support high speed Internet service with easily installed indoor antennas. It was also shown [6] that, specially for scenarios with significant obstructions (trees or high-rise buildings), a wireless mesh network can significantly improve the coverage in comparison with a point-to-multipoint (e.g. IEEE 802.16) solution. It is true that, for mesh network between WRPs, WRP should have several directional antennas in each direction. However, omni-directional antennas are inexpensive and simple to build and use and directional antennas allow wireless mesh networks to reduce the interference between simultaneous transmissions to improve the link budget and range and/or to reduce the transmission power [7]. Star network can also provide solution using a centralized hub in a star network. But, in this case, the hub requires larger cost deployments for maintenance and also reliability on a single node will be risky for the whole network. So, WRPs should gradually use mesh NLOS systems. Advanced modulation techniques like Orthogonal Frequency Division Multiplexing (OFDM) 
with space-time coding or turbo coding can be used here to maximize the available radio spectrum to support broadband communications.

The existing fiber optic backbone of Bangladesh Railway, BTTB and Optical Fiber Wires under high tension power transmission lines (OPGW) of Power Grid Company of Bangladesh (PGCB) are jointly to be used for connectivity to the Internet backbone with fiber optic submarine cable through SEA-ME-WE-4 Consortium [1]. So, fiber backbone as a bus with wireless feeds can be considered to design the backbone architecture of rural areas as shown in Fig.2. That requires three types of radios/antennas: those interfacing directly with the fiber bus, those in the villages and intermediate radios. The fiber bus will act as the central server, RRSs will be the intermediate backbone radios, WAPs will be the intermediate radios and finally WRPs will work as the village radios. They will function accordingly to our proposed model.

\subsection{Last-mile connectivity cost comparison}

A comparative table of data for costs of deploying and operating both the wired and wireless networks in the last-mile is listed below:

Table 1. Last-mile connectivity comparison

\begin{tabular}{|l|l|l|}
\hline Parameter & $\begin{array}{l}\text { Wireless } \\
\text { Connection }\end{array}$ & $\begin{array}{l}\text { Wired(Fiber- } \\
\text { optic) } \\
\text { Connection }\end{array}$ \\
\hline Throughput & $2-5 \mathrm{Mbps}$ & $100 \mathrm{Mbps}$ \\
\hline $\begin{array}{l}\text { Monthly } \\
\text { Maintenance } \\
\text { Costs }\end{array}$ & $\$ 200-500$ & $\$ 3000-5000$ \\
\hline $\begin{array}{l}\text { Installation, } \\
\text { per site }\end{array}$ & $\$ 500-1000$ & $\$ 2000-4000$ \\
\hline $\begin{array}{l}\text { External } \\
\text { Wiring }\end{array}$ & $\begin{array}{l}\$ 650-4000, \text { per } \\
\text { site }\end{array}$ & $\begin{array}{l}\$ 20000-50000 \\
\text { per square km }\end{array}$ \\
\hline $\begin{array}{l}\text { Equipment } \\
\text { Cost, per site }\end{array}$ & $\$ 2000-6000$ & $\$ 1500-5000$ \\
\hline Distance limit & $20-40 \mathrm{~km}$ & $20-30 \mathrm{~km}$ \\
\hline
\end{tabular}

It is seen from the table, as the remote corners of the rural areas are difficult to reach and mostly electricity or power sub stations are also not available, the fiber optic cable installation and maintenance will be very difficult and costs will be huge therefore for last mile fiber optic deployment. Fig. 3 represents the comparative plot between wireless and wired deployment in the last mile rural connectivity. The costs comparison has been plot taking the maximum values shown in the table for each cost type.

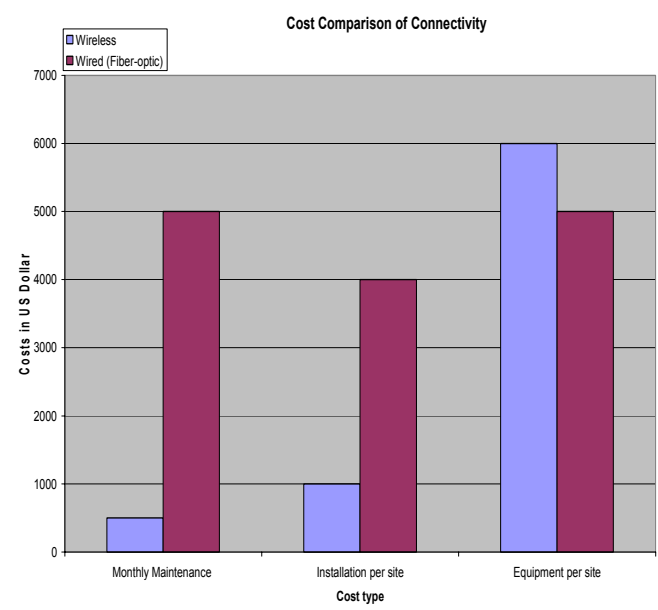

Figure 3. Cost comparison between wired and wireless network

\section{Implications on the rural community}

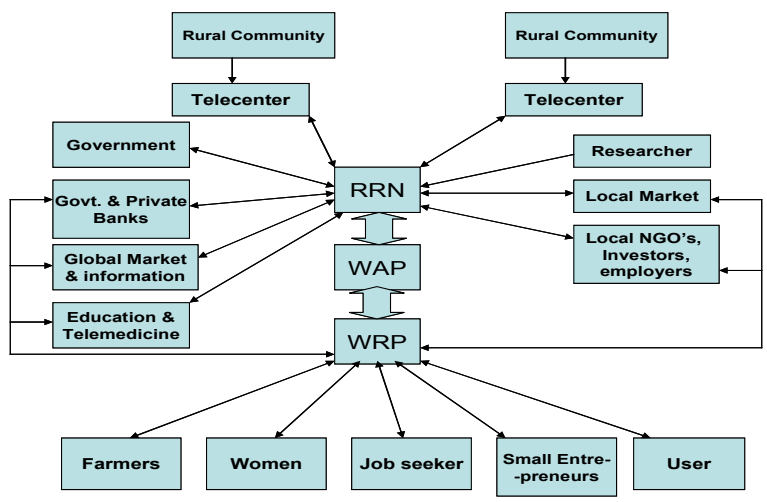

Figure 4. ICT based wireless network model for the rural development

ICTs in the form of telecenters at each WAP can act as a nodal point for community connectivity, local capacity building and serve as hubs for applications such as distance education, telemedicine and support to small, medium sized and microcredit enterprises, promotion of electronic commerce, environmental management and empowerment of women and youth. Farmers can get useful information through WRP or telecenters in WAP in the form of crop care and animal husbandry, fertilizer and feedstock inputs, drought mitigation, pest control, irrigation, weather forecasting, seed sourcing and market prices. The Maharashtra State Government in India has plans to link 40,000 villages with Agronet, a specially software package for farmers that aims to provide the latest information on agriculture [3]. 
In the proposed model, the telecenters will have the Internet connectivity as well as WRP access. The connection between the RRN and telecenters can be made in both of the ways. So, by using WRP access, separate mobile networks will not be necessary for the bidirectional communication between the telecenters and the users. Requests for any information from the villagers' WRPs will reach to RRN. RRN will send the request to telecenter if the information needed is not found in the RRN server. The telecenter staffs will search the information and then send the information back to RRN and RRN will send it to the particular WRP through SMS, MMS etc. Thus, m-commerce where buying and selling of goods and services using mobile device is accomplished; can be used from this proposed model by the WRPs of rural people in the form of SMS, MMS, micro-payments, information services etc. Next generation wireless technology usage can offer secured electronic transactions in $\mathrm{m}$ commerce. As most of rural people are unable to operate computers, telecenter staffs can educate the people with basic knowledge to use Internet. Language may be a problem here because most of them also don't know English. So, preparing updated information in local language becomes important here to make the telecenters useful. Selling of handicrafts and other products in local and international markets via our proposed model can be very useful for women empowerment in rural areas. Unemployed and young people can discover job opportunities by getting updated information at their WRPs or telecenters or they can be employed in the new jobs created though the deployment of ICTs. GPs Village Phone (VP) concept is a testimony of this initiative and as of August 2005, there are more than 165,000 VP subscribers in Bangladesh. Also, Chilean people are learning how to use telecenters to help in their current job or to find new jobs [2].

RRN and WAP will also gradually train each subscriber to provide him with a homepage under each RRS domain. This will eventually help them to introduce their products in the global market. Under each WAP, each rural community can also think about a rural tourist information website representing the tourist spots of that particular area and thereby creating job opportunities along with selling traditional clothes and products to the global market. A brief description of the process has been shown in Fig.4 above.

\section{Conclusion}

In this paper, a cost effective model has been proposed in a gradual development approach involving the next generation wireless technology keeping in mind the existing infrastructure of ICT in the target country. The proposed model is cost-effective in several ways. First of all, to minimize costs mobile units are considered to be end-point stationary devices (WRPs) which will be located in important locations of a village using LTF. Secondly, the existing telecommunication and IP backbone infrastructure of the target country was used extensively in the model to avoid more costs of deploying new backbone. The fiber optic backbone so far established in the target country has been taken as a backbone for the rural wireless connectivity model. Also, a comparative analysis of available technologies has been in section 3.3 and 3.4 to provide the most cost-effective solution for the proposed model. Developing countries of the world are facing almost the same socio-economic infrastructure, so similar approach can be taken by them as well.

\section{References}

[1] Ahmed F., "The Technical Issues Related to ICT Development in Bangladesh", National Conference on InterUniversity IT Professionals, http://www.ugc.org/farruk.ppt, Dhaka, Bangladesh, 2003.

[2] Fierro, L.A., "Developing Countries and ICTs", IEEE Potentials, Volume 24, no. 2, April-May 2005, pp 5.

[3] W.R.Harris, Information and Communication Technologies for Poverty Alleviation, UNDP-APDIP, Kuala Lumpur, 2004.

[4] J. F. Proenza, "The Road to Broadband Development in Developing Countries is Through Competition Driven by Wireless and VOIP", Presented paper in Wireless Communication and Development: A Global Perspective, Annenberg Research Network on International Communication, California, USA, October 7-8, 2005.

[5] B.Raman \& K. Chebrolu, "Design and Evaluation of a new MAC protocol for long-distance 802.11 mesh networks", 11th Annual International Conference on Mobile Computing and Networking Paper (MOBICOM), Cologne, Germany, Aug/Sep. 2005, pp 156-169.

[6] D. Beyer, "Fundamental characteristics and benefits of wireless routing ("mesh") networks", Proc. of the International Technical Symposium of the Wireless Communications Association, California, USA, Jan. 2002.

[7] Mihail L. Sichitiu, "Wireless Mesh Networks: Opportunities and Challenges," The tenth IEEE symposium on computers and communications, Spain, June 2005. 